\title{
ISOLATION AND IDENTIFICATION OF SOME POSSIBLE CAUSATIVE AGENTS OF SWOLLEN HEAD SYNDROME (SHS) IN BROILER CHICK- ENS IN EGYPT
}

\author{
Nasif S. Abdelmoez ${ }^{1}$, M. M. Shawky², Heba A. Abdelhady³ , M. A. Lebdah², \\ Selim S. Salama ${ }^{1^{*}}$
}

${ }^{1}$ Central Laboratory for Evaluation of Veterinary Biologics, Abbasia, Cairo - Egypt, ${ }^{2}$ Avian and Rabbit Medicine Dept. Faculty of Vet. Med., Zagazig University, Egypt, ${ }^{3}$ Animal Health Research Institute (AHRI), Alexandria branch, Egypt

*Corresponding author, E-mail: selimsalama2000@yahoo.com

\begin{abstract}
The current study was designed to detect, isolate and identify the etiological agents of SHS in chicken flocks in Egypt. Clinical samples, including the trachea, lung and choanal cleft swabs, from different flocks, ages and localities were collected from non-vaccinated commercial broiler flocks with respiratory signs then transmitted directly to the laboratory for further examination. Avian metapneumovirus RNA (aMPV RNA) was extracted then amplified using one step RT-PCR using both subtype A and B (G gene) primers then differentiation occurred by real time PCR (qPCR). Swab samples from subcutaneous edema and exudates were directly cultured and the suspected bacterial colonies were biochemically identified then confirmed by PCR. Four samples were positive and one doubtful for aMPV using RT-PCR confirmed by qPCR. Bacteria isolation revealed that out of 40 samples, 16 samples were positive for E.coli, 4 samples were positive for $P$. aeruginosa, 6 samples were positive for $P$. mirabilis, 4 were mixed $E$. coli and $P$. aeruginosa, 8 were mixed $E$. coli with $P$. mirabilis and 2 samples were mixed $P$. mirabilis and $P$. aeruginosa. Depending on these findings, we could prescribe a preliminary guide to decrease SHS outbreaks by primary control of bacterial complication.
\end{abstract}

Key words: Swollen Head Syndrome; PCR; bacterial complication

\section{Introduction}

The respiratory diseases considered one of the most serious problems affecting chicken flocks resulting in severe economic losses. Several etiological agents like viruses and bacteria have been incriminated. Among viruses infecting broiler flocks, avian metapneumovirus $(a M P V)$, which cause a disease entitled as Turkey Rhinotracheitis (TRT) in turkey and swollen head syndrome (SHS) in chickens (1). In
Egypt, aMPV infection was diagnosed through detection of the infected broiler chickens by RT-PCR that revealed circulation of both aMPV subtypes A and B in turkey flocks (2 and $3)$. Unfortunately till now, no identification to aMPV subtype circulating in broiler chickens in Egypt.

Swollen head syndrome is a disease of upper respiratory tract affecting broilers and broiler breeders and characterized by swelling of head 
and facial edema which resulted from accumulation of inflammatory exudate beneath the skin of the head in response to secondary bacterial infection usually E. coli following the initial upper respiratory viral infection and it has become a problem in many countries in the last few years. SHS has been described as a multi-factorial disease. The initial lesion mainly caused by virus, while the clinical signs were a consequence of bacterial complications. The severity of the disease depends on presence of some environmental factors such as accumulation of ammonia, dust, overcrowding and bad ventilation. So, $a M P V$ cause the initial damage of the respiratory tract, allowing invasion of bacteria, especially E.coli, which were responsible for the clinical disease (4). SHS is a disease of chickens of all ages mainly 4 - 6 weeks old with morbidity may reach to $10 \%$ and mortality about $2 \%$ (5). The affected birds showed depression, decreased feed intake, nasal exudate, sneezing, coughing and conjunctivitis followed by facial edema which start around eye extending over the head and descending to submandibular tissues (6).

Therefore, the current study was designed to detect, isolate and identify the etiological agents of SHS in chicken flocks in Egypt.

\section{Materials and methods}

\section{Virus isolation and identification}

\section{Clinical Samples}

Samples were collected from non-vaccinated commercial broiler flocks with respiratory signs such as, sneezing, coughing, tracheal rales, nasal and ocular discharges, swollen infraorbital sinuses and foamy conjunctivitis then transmitted directly to the laboratory for further examination. Samples included the trachea, lung and choanal cleft swabs. Samples were collected from different flocks, ages and localities.

\section{Extraction of viral RNA}

Procedure adopted using QIAamp Viral RNA Mini Kit (Cat\# 52906) according to manufacture instructions using reagents provided in the kit.

\section{Amplification of aMPV RNA}

The reaction was prepared according to QIAGEN One Step RT-PCR (Cat\# 204443) manufactures instructions. The reaction was performed for both subtype $\mathrm{A}$ and $\mathrm{B}$ ( $G$ gene) as following: reverse transcription $\left(42^{\circ} \mathrm{C} / 30 \mathrm{~min}\right)$, initial denaturation step $\left(95^{\circ} \mathrm{C} / 10 \mathrm{~min}\right)$, followed by 40 cycles of denaturation $\left(95^{\circ} \mathrm{C} / 1\right.$ $\mathrm{min})$, annealing $\left(54^{\circ} \mathrm{C} / 1 \mathrm{~min}\right)$, extension $\left(72^{\circ} \mathrm{C}\right.$ $/ 1 \mathrm{~min})$ and final extension $\left(72^{\circ} \mathrm{C} / 10 \mathrm{~min}\right)$. The PCR product was then analyzed by electrophoresis in $1.5 \%$ agarose gel with 100 bp DNA ladder using TAE running buffer and 100 volts for 40-50 min. The ethidium bromide stained PCR bands were visualized in the agarose gel using UV transilluminator.

Primers used for $a M P V$ RT-PCR were designed as described by (7) $\mathrm{Ga}(\mathrm{gf})$ - forward CCGGGACAAGTATCTCTATGG for all subtypes, G2(gaf)-reverse CCACACTTG AAAGATCTACCC for A subtype and G12(gb)- reverse CAGTCGCCTGTAATC TTCTAGGG for B subtype. Also probes used for $a M P V$ real time PCR were designed following (8) as:

SHf: TAGTTTTGATCTTCCTTGTTGC

SHr: GTAGTTGTGCTCAGCTCTGATA

MB-SH-A:HEXCGCGATCGTGGAC-

CTCCT

GCACTGTGGATCGCG-Iowa Black FQ

MB-SH-B:FAMCGCGATCATTGTGACAGC

CAGCTTCACGATCGCG-Iowa Black FQ.

qPCR was done using SuperScript ${ }^{\circledR}$ III Platinium ${ }^{\circledR}$ One-Step qPCR system-Invitrogen (Cat\# 11732-088) according to manufacture instructions.

\section{Sampling and bacterial isolation}

Swabs were collected aseptically from subcutaneous edema and sinuses exudate. Collected samples were inoculated in nutrient broth then $24 \mathrm{hr}$ incubation at $37^{\circ} \mathrm{C}$ aerobically. Loopfull transferred onto nutrient agar, MacConkey agar and blood agar media and incubated for $24 \mathrm{hr}$ aerobically at $37^{\circ} \mathrm{C}$. Suspected colonies were identified by cultural, morphologically (9), biochemically (API 20E) (10), and molecularly by PCR. 
Polymerase Chain Reaction (PCR)

Extraction of bacterial DNA from E.coli were propagated by inoculation on nutrient broth then injected subcutaneously in mice followed by re-isolation from heart and liver on MacConkey agar. A single bacterial colony was transferred into $2 \mathrm{ml}$ of nutrient broth and incubated overnight at $37^{\circ} \mathrm{C}$. Culture was centrifuged and the bacterial pellet was re-suspended in $400 \mu 1$ and DNA was extracted using DNA Extraction Kit (Presto ${ }^{\mathrm{TM}}$ Mini gDNA Bacteria Kit Cat\# GBB101).

$E$. coli isolates were screened for presence of $16 \mathrm{~s} r R N A$ gene using specific primers $($ Eco-1F, GACCTCGGTTTAGTTCACAGA and Eco2R, CACACGCTGACGCTGACCA giving rise a specific PCR product at a size of $585 \mathrm{bp}$ (11). The cyclic conditions were performed as previously described (12).

Vitek2 compact system method for bacterial identification

Bacterial identification by Vitek-2 compact system was done according to the manufacture's instruction (Biomeriux VITEK-2 Compact ref Manual - Ref-414532)

\section{Results}

\section{Clinical signs}

The suspected samples were collected from birds showing coughing, snicking, wet or frothy eyes, conjunctivitis, sneezing, facial edema, unilateral or bilateral swelling of infraorbital sinuses and some chickens showed swelling of their entire face including wattles. At the same concern the postmortem lesions of suspected dead cases revealed often yellowish extensive gelatinous to purulent edema of subcutaneous tissues of head region, sinusitis, tracheitis, perihepatitis, pericarditis and few cases showed pneumonia and air saculitis.

\section{Detection of aMPV by RT-PCR}

The genomic RNA of $a M P V$ was tested using $\mathrm{Ga}$ and $\mathrm{G} 2$ primers for subtype A that revealed all samples were negative while with using Ga and G12 primers for subtype B only 4 samples were positive giving rise to a product of $312 \mathrm{bp}$ (Fig. 1).
Detection, confirmation and subtyping with $q P C R$

The positive, doubtful and negative samples were re-examined by qPCR for accurate confirmation, 5 samples out of 40 were positive and confirmed $a M P V$ subtype B isolates (Table 1, Fig.2).

\section{Colonial characteristics of isolated bacte-} rial associated with SHS infection

Several bacterial causative agents were isolated from suspected samples on different media as shown in Table (2). The suspected colonies of $E$. coli showed slight turbidity on nutrient broth, circular, smooth surface, mucoidy colonies, and greyish in color on nutrient agar while on MacConkey agar showed Pink colonies due to lactose fermentation. Meanwhile the suspected colonies of Pseudomonas spp. showed abundant growth and turbidity with bluish green color on nutrient broth and convex, glistening, translucent with bluish green color on nutrient agar while on MacConkey agar it showed pale colonies of non-lactose fermenter. Proteus spp. showed uniform turbidity with a slight powdery deposit and an ammonical odour on nutrient broth while on the nutrient agar made swarms intermittently in the characteristic step-like pattern across the agar surface but it looked like pale colonies with non-lactose fermentation on MacConkey agar.

\section{Bacterial isolation and biochemical identi- fication}

Frequency of isolation as confirmed by Vitek2 assay and PCR was illustrated in Table (2). The identification results revealed that 28 samples out of 40 were E. coli (16 as single infection, 8 mixed infection with $P$. mirabilis and 4 mixed infection with $P$. aeruginosa). Also 16 samples out of 40 were $P$. mirabilis ( 6 as single infection, 8 mixed infection with $E$. coli and 2 mixed infection with $P$. aeruginosa). Finally 10 isolates out of 40 were $P$. aeruginosa (4 as single infection, 4 mixed infections with $E$. coli and 2 mixed infection with $P$. mirabilis). The amplified PCR product of suspected E. coli samples were 585 bp using the specific primers (Fig. 3). 
Table 1: Frequency of positive samples as detected by qPCR

\begin{tabular}{lcccc}
\hline$A M P V$ type & $\begin{array}{c}\text { No. of tested } \\
\text { samples }\end{array}$ & $\begin{array}{c}\text { No. of +ive } \\
\text { samples }\end{array}$ & $\begin{array}{c}\text { No. of -ve } \\
\text { samples }\end{array}$ & $\begin{array}{c}\text { Detection } \\
\text { percentage }\end{array}$ \\
\hline$a M P V$ Subtype A & 40 & 0 & 40 & $0 \%$ \\
$a M P V$ Subtype B & 40 & 5 & 35 & $12.5 \%$ \\
\hline
\end{tabular}

$\%$ calculated according to the number of positive to tested samples.

Table 2: Frequency and isolation rate of some bacterial isolates either single or mixed complication associated with $A M P V$ infection

\begin{tabular}{lllll}
\hline Bacterial type & & $\begin{array}{l}\text { Tested } \\
\text { flocks No. }\end{array}$ & $\begin{array}{l}\text { Frequency } \\
\text { of isolation }\end{array}$ & $\begin{array}{l}\text { Percent of } \\
\text { isolation }\end{array}$ \\
\hline E. coli & 40 & 16 & $40 \%$ \\
P. aeruginosa & 40 & 4 & $10 \%$ \\
P. mirabilis & E.coli + P. aeruginosa & 40 & 6 & $15 \%$ \\
\hline \multirow{2}{*}{$\begin{array}{l}\text { Mixed infec- } \\
\text { tions }\end{array}$} & E.coli + P. mirabilis & 40 & 8 & $10 \%$ \\
& P. mirabilis + P. aeruginosa & 40 & 2 & $20 \%$ \\
\hline
\end{tabular}

$\%$ calculated according to the number of positive to tested samples.

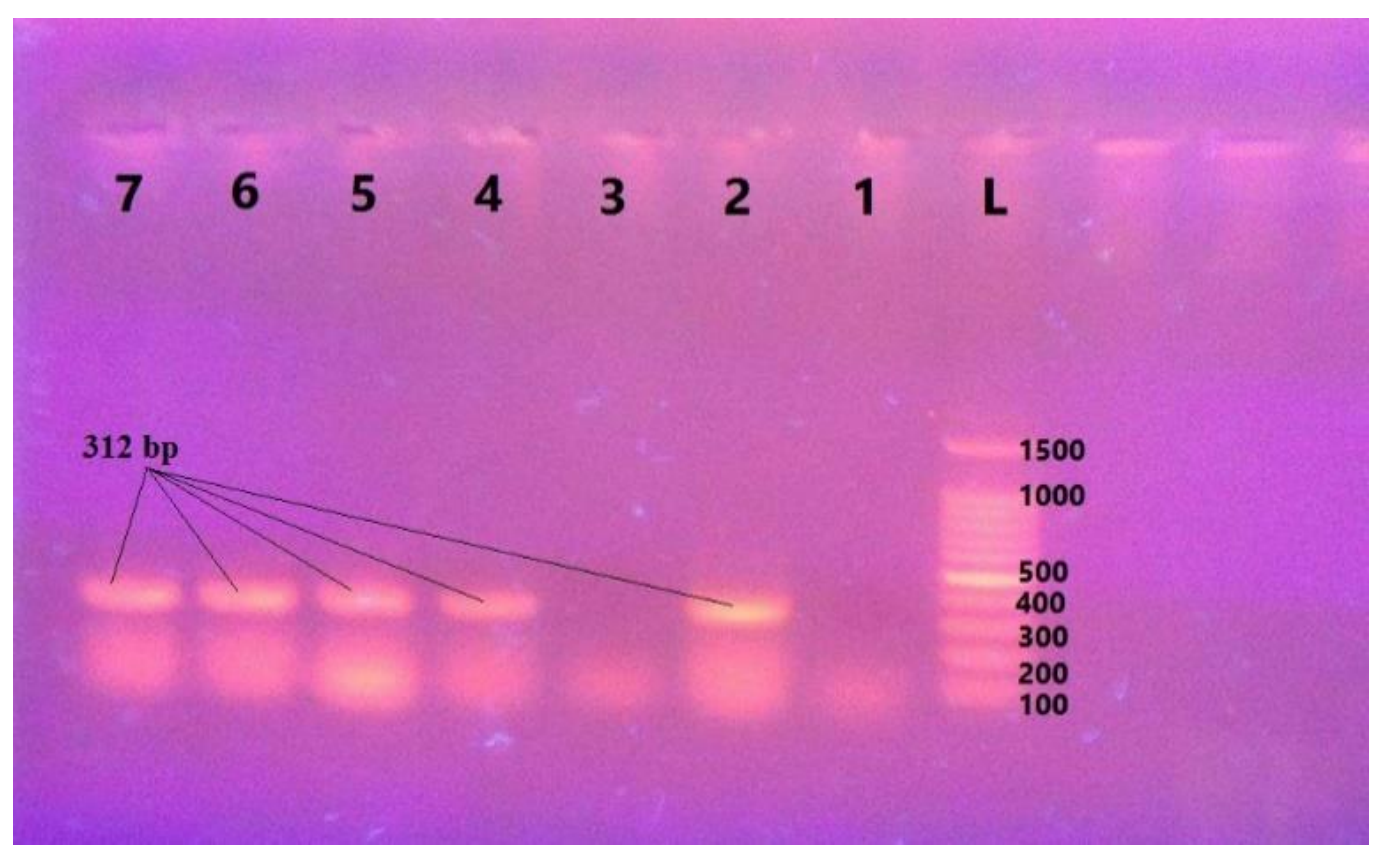

Figure 1: Ethidium bromide-stained $1.5 \%$ agarose gel showing RT-PCR amplification products of $a M P V$ subtype B (312 bp). (L: 100 bp DNA Ladder; Lane 1: Negative control; Lane 2: Positive control; Lane 3: doubtful sample and Lanes 4, 5, 6 and 7 were positive sample 


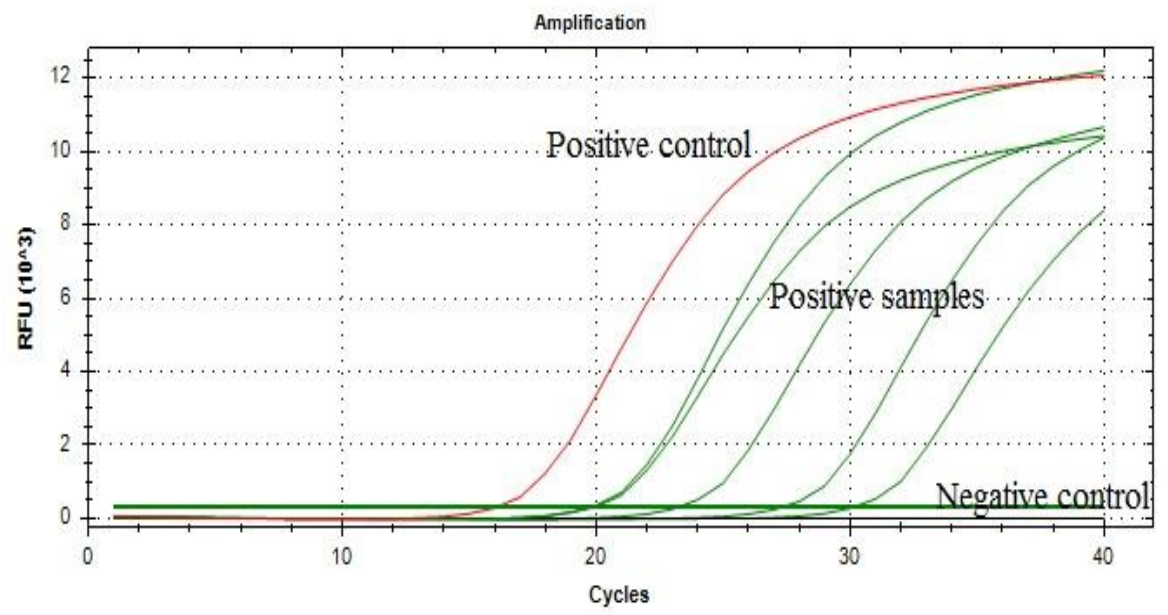

Figure 2: Amplification curves of qPCR showing cycle threshold $(\mathrm{Ct})$ values of $a M P V$ isolates where red line: positive control; green lines: positive samples and black line: negative control

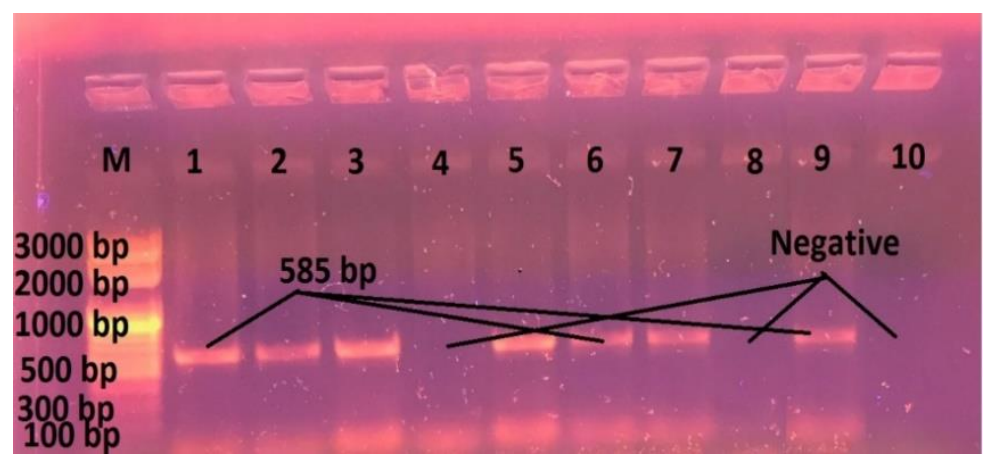

Figure 3: Ethidium bromide-stained 1.5\% agarose gel showing PCR amplification products of 16s $r R N A$ gene of E.coli (585 bp). M, marker; positive samples are 1, 2, 3, 5, 6, 7 and 9; while negative samples are 4,8 and 10

\section{Discussion}

Infection associated with respiratory tract has significant economic impact on poultry production worldwide. SHS is a disease of upper respiratory tract and considered as one of these problems in last few years. The disease affects broilers and broiler breeders which resulted in inflammatory exudate beneath the skin (13). SHS has been described as a multi-factorial disease where the initial lesion mainly caused by $a M P V$, while the clinical signs are a consequence of bacterial complications and the severity of the disease depends on environmental factors (4).

This study was planned to detect and try to isolate some of the possible etiological agents of swollen head syndrome from different 40 broiler flocks showing swollen heads and respiratory manifestations with frothy conjunctivitis, snicking, wet or frothy eyes, sneezing, facial edema, unilateral or bilateral swelling of infraorbital sinuses. Samples included lung tissues, trachea and choanal cleft swabs and scrabs from sinuses and turbinates. These observations were parallel to the findings obtained by (5) who reported that, the first symptoms of swollen head syndrome in broiler chickens were sneezing, redness of conjunctiva with swelling of lacrimal glands followed by subcutaneous edema of head starting around eye. Similar findings had been reported by (14). At the same concern (4) reported that the severity of the SHS depends on environmental factors.

The postmortem lesions of suspected freshly dead cases revealed often yellowish extensive gelatinous to purulent edema of subcutaneous 
tissues of head region and extended in some cases to include the submandibular area, sinusitis and tracheitis. On the other hand, few cases showed perihepatitis and pericarditis, pneumonia and airsaculitis. These findings were the same that recorded by (15). Also (16) observed other lesion in the form of various amounts of casious exudate in lacrimal gland. In addition to (17) found that, under field conditions gross pathology depends largely on the presence of secondary infections in form of airsaculitis, pericarditis, perihepatitis and pneumonia.

Regarding detection of $a M P V$ using conventional RT-PCR, only 4 samples out of 40 in a percentage of $10 \%$ were detected meanwhile, when the same 40 samples were examined using qPCR, 5 samples out of the collected 40 flock samples were detected, in a percentage of $12.5 \%$ and the detected virus isolate belonged to subtype $\mathrm{B}$ of $a M P V$. The difference between the two results could be attributed to the higher sensitivity of qPCR than conventional PCR. Parallel results were recorded in Egypt by (18) who detected TRT antibodies in broiler chickens from ten farms showing swollen heads and in other five healthy broiler farms in different Egyptian provinces using two different ELISA kits indicating seroprevalences of virus in Egypt. Also (3) detected the TRT virus ( $a M P V)$ subtype B in turkey flocks in Egypt. On the other hand, our results were in agreement with that of (19) who detected $a M P V$ subtype $\mathrm{B}$ in 17 broiler flocks out of 133 examined flocks constituting about $12.5 \%$ of tested flocks in Jordan.

Regarding bacterial complications in the examined 40 flocks regardless to presence or absence of $a M P V$ infection, our results revealed that twenty eight samples out of 40 were positive for $E$. coli isolation (16 as single infection, 8 mixed infections with $P$. mirabilis and 4 mixed infection with $P$. aeruginosa), sixteen samples out of 40 were carried $P$.mirabilis (6 as single infection, 8 mixed infection with $E$. coli and 2 mixed infection with $P$. aeruginosa) and ten isolates out of 40 were infected with $P$. aeruginosa (4 as single infection, 4 mixed infection with $E$. coli and 2 mixed infection with P. mirabilis).
Concerning the secondary bacterial infection accompanying the $a M P V$ infection among the 5 infected flocks, the $E$. coli was the predominant secondary bacterial spp. in the 5 flocks either alone in 2 flocks or complicated with either $P$ .mirabilis (2 flocks) or P. aeruginosa as in one flock. Similar results were recorded by (20) and (21) who isolated pure E. coli culture from cases of $a M P V$ infection. In the same context many authors reported mixed bacterial infection complicating $a M P V$ infection in broilers including (22) who had isolated E. coli, Pseudomonas spp. besides Moraxella spp. from SHS cases. Also, (23) who had isolated P. aeruginosa, E. coli, $P$. mirabilis and Staphylococcus spp. complicating viral infection from young chicken during 1992 with SHS. Furthermore, (24) could isolate Pneumovirus for the first time together with $E$. coli and $P$.mirabilis from a broiler flock with swollen head syndrome in Japan.

Regarding the other 35 flocks that were negative for $a M P V$ and showing SHS signs, our results revealed incrimination of $E$. coli alone or mixed with $P$. mirabilis and /or P. aeruginosa to be the causative agents of SHS in that chicken flocks besides the recorded bad environmental and/or managemental factors. These findings were parallel to those obtained by (25) who reported that TRT virus did not play a causal role in SHS in commercial broilers in Greece but other bacterial agents together with bad environmental factors seemed to be essential in the occurrence and severity of the disease.

The lower detection rate of $a M P V$ from the affected broiler flocks may be due to short period of presence of that virus in the tissues of affected birds, nearly not more than 4 days, in addition to presence of secondary bacterial infection in most of affected cases. From the above mentioned findings, we could prescribe a preliminary guide to subside and decrease SHS outbreaks by primary control of bacterial complication either by application of biosafety and biosecurity measures, optimization of environmental factors, application pf available vaccination programs or curative and prophylactic treatment will help and support the reduction of 
prevalence of SHS infections among broiler and broiler breeder flocks in Egypt.

\section{Conclusion}

It could be concluded that these results confirming the prevalence of $a M P V$ subtype $\mathrm{B}$ among poultry flocks and its detection for the first time among broiler chickens in Egypt, through isolation, identification of the $a M P V$ virus using RT-PCR and qPCR. In addition to, isolation and identification of some bacterial co-infection as E. coli, P. mirabilis and P. aeruginosa using traditional methods, PCR and Vitek2 compact system.

\section{Conflict of interest}

The authors declare that they have no conflict of interest.

\section{References}

1. Picault I.P.; Giraud P.; Deouin P.; Guittet N.; Benjean H.; Lamande L.; Toquin D and Gueguen C. Isolation of turkey rhinotracheitis like virus from chickens with swollen head syndrome. 1987; Vet. Rec., 121: 135.

2. Abdel-Azeem A.A.S.; Franzo G.; Dalle Zotte A.; Drigo M.; Martini M. and Cecchinato M. First evidence of avian metapneumovirus subtype $\mathrm{A}$ infection in turkeys in Egypt. Trop Anim Health Prod., 2014; 46:1093-7.

3. Arafa A.; Mady W.; Hussein A.; Tamam S. and Madbouly H. Molecular Characterization of Vaccine-Derived Mutants of Avian Metapneumoviruses Isolated from Turkeys in Egypt. Am. J. Virolo., 2015; 4 (1): 1.11.

4. Nakamura K.; Mase M.; Tanimura N.; Yamaguchi S. and Yuasa N. Attempts to reproduce swollen head syndrome in specific pathogen free chickens by inoculating with Escherichia coli and/or turkey rhinotracheitis virus. Avian Pathol., 1998; 27: 21-7.

5. Morley A.J. and Thomson D.K. Swollen head syndrome in broiler chickens. Avian Dis., 1984; 28 : 238-43

6. Kuhne P. Ways to control avian metapneumovirus. International poultry production, 2009; 17 (3): 7-9.

7. Bayon-Auboyer M.H.; Jestin V.; Toquin D.; Cherbonnel M. and Eterradossi N. Comparison of F-, G- and N-based RT-PCR protocols with conventional virological procedures for the detection and typing of turkey rhinotracheitis virus. Arch. Virol., 1999; 144: 1091-109.

8. Cecchinato M.; Lupini C.; Pogoreltseva O.S.; Listorti V.; Drigo A.M. and Catelli E. Development of a real-time RT-PCR assay for the simultaneous identification, quantitation and differentiation of avian metapneumovirus subtypes A and B. Avian Pathol., 2013; 42 (3): 283-9.

9. Cruickshank R.; Duguid J.P.; Marmion B.P. and Swain R.H.A. Medical Microbiology. The Practice of Medical Microbiology. $12^{\text {th }}$ Ed. Vol. II Churchill Livingstone, Edinburgh, London and New York.1975.

10. Ghanbarpour R.; Salehi M. and Oswald E. Virulence genotyping of $E$. coli isolates from avian cellulitis in relation to phylogeny. Comp. Clin. Pathol., 2010; 19:147-53.

11. Tonu NS, Sufian MA, Sarker S, Kamal MM, Rahman MH, and Hossain MM. Pathological study on colibacillosis in chickens and detection of E. coli by PCR. Bangl J Vet Med. 2011; 9: 17-25.

12. Khatun N.M.; Mahbub E.; Elahi A.T.M.; Ahmed S.; Parvej M.S.; Akhter S.; Ansari W.K. and Ali M.S. Frequency of drug resistant E. coli isolated from commercial chickens in Bangladesh. International journal of Natural and Social Sciences, 2015; $2(4): 1-5$.

13. Seifi $\mathrm{S}$ and Boroomand $\mathrm{Z}$. The role of avian metapenumo-virus in respiratory complex disease circulating in broilers in Northern Iran. Trakia J. Sci., 2015; No 2, pp 175-9.

14. Homayounfar N.; Shoushtari H.; Charkhkar S. and Bozorgmehrifard M. Detection by reverse transcriptase-polymerase chain reaction and molecular characterization of avian metapneumovirus in Chicken flocks in Iran: WALIA J., 2015; 31 (S3): 170-4

15. Jirjis F.F.; Noll S.L.; Halvorson D.A.; Nagaraja K.V. and Shaw (D.P. 2002): Pathogenesis of avian pneumovirus infection in turkeys. Vet. Pathol., 39: 300-10.

16. Nunoya T.; Tajima M.; Izuchi T.; Takahashi K.; Otaki Y.; Nagaswa Y. and Hakogi E. Pathology of a broiler disease characterized by swollen head. J. Vet. Med. Sci., 1991; 53: 347-9.

17. Jones R.C. and Rautenschlein S. Avian metapneumovirus. In: Swayne, D.E., John R. Glisson, Larry R. Mcdougald, J.R. Glisson, Lisa K. Nolan, Suarez, D.L. and Nair, V. (eds.) Diseases of poultry. $13^{\text {th }}$ ed. Ames: John Wiley and Sons, Inc.2013.

18. Aly M. M.; El-Zaher A.A. and Amin A. Studies on swollen head syndrome in Egypt. 1. Serological survey and comparison between two 
ELISA kits for detection of antibody. Veterinary Medical Journal Giza, 1997; 45 (2): 251-8.

19. Gharaibeh S.M. and Algharaibeh G.R. Serological and molecular detection of avian pneumovirus in chickens with respiratory disease in Jordan. Poult. Sci., 2007; 86: 1677-1681.

20. Hafez H.M. and Löehren U. Swollen head syndrome: clinical observations and serological examinations in West Germany. Dtsch. Tierarztl. Wochenschr., 1990; 97: 322-4.

21. Al-Ankari A.S.; Al-Ramadan A.M. and ElDemerdash Risk factors associated with prevalence of swollen head syndrome (SHS) in broiler chickens in eastern province-Saudi Arabia. Int. J. Poult. Sci., 2004; 3 (10): 646-50.
22. McDougall J.S. and Cook J.K. Turkey rhinotracheitis: preliminary investigations. Vet. Rec., 1986; 118: 206-7.

23. Goodwin M.A. and Waltman W.D. Clinical and pathological findings in young Georgia broiler chickens with oculofacial respiratory disease (socalled swollen head). Avian Dis., 1994; 38: 376-8.

24. Tanaka M.; Takuma H.; Kokumai N.; Oishi E.O.B.; Hiramatsu K. and Shimizu Y. Turkey rhinotracheitis virus isolated from broiler chicken with swollen head syndrome in Japan. J. Vet. Med. Sci., 1995; 57: 939-41.

25. Georqiades G., Iordanidis P., Koumati M. Cases of S-H-S in broiler chickens in Greece. Avian dis. 2001; 45 (3): 745-50. 